\title{
Modular System Modeling for Quantitative Reliability Evaluation of Technical Systems
}

\author{
S. Neumann \\ L. Wöll \\ A. Feldermann \\ F. Straßburger \\ G. Jacobs
}

${ }^{1}$ RWTH Aachen University, Institute for Machine Elements and Machine Design, Schinkelstr. 10, DE-52062 Aachen, Germany. E-mail: \{neumann,Iwoell,feldermann,strassburger,jacobs\} @ime.rwth-aachen.de

\begin{abstract}
In modern times, it is necessary to offer reliable products to match the statutory directives concerning product liability and the high expectations of customers for durable devices. Furthermore, to maintain a high competitiveness, engineers need to know as accurately as possible how long their product will last and how to influence the life expectancy without expensive and time-consuming testing. As the components of a system are responsible for the system reliability, this paper introduces and evaluates calculation methods for life expectancy of common machine elements in technical systems. Subsequently, a method for the quantitative evaluation of the reliability of technical systems is proposed and applied to a heavy-duty power shift transmission.
\end{abstract}

Keywords: Reliability, Failures, Lifetime, Transmission

\section{Introduction}

Even though the design and development time frames of new products become shorter and shorter, it is mandatory to create a competitive product that matches customer's demands. As the products become more complex with each life cycle, reliability is a big challenge. Problems in achieving this target are reflected in the growing number of recall campaings by car companies (see Figure 1). This trend implies that the high complexity of new products is not under control, resulting in a decrease in reliability.

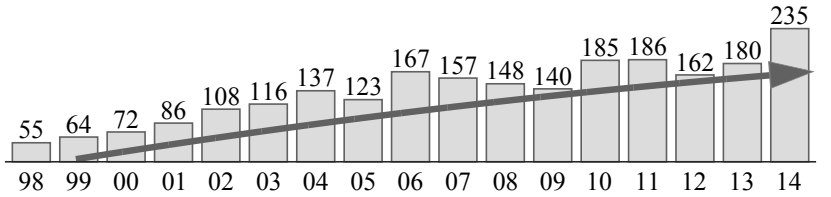

Figure 1: Number of recall campaigns of cars in Germany from 1998-2014, data from DAT (2015)
When developing an entire new car, the subsystem "Vehicle Transmission" causes 1-10\% of the total development costs Dette and Kozub (2000). To establish a reliable forecast of the expected failure rate during the development process, tests with a large number of transmissions would be necessary. Those tests, however, are rarely considered due to costs and time. Hence, a quantitative assessment of the transmissions' reliability is required, which allows a durable and therefore cost efficient design of the components. Especially for the design of gear shafts, a very high fatigue strength is common. This kind of over-sizing causes unwanted costs, weight and additional occupied room in a transmission Naunheimer et al. (2007), which should be avoided.

The initially mentioned trend in rising numbers of recalls is in contrast to the customer's demands. Customers consider reliability as the most important requirement when buying a brand new car DAT (2015). Therefore, the creation and application of methods for reliability evaluation are mandatory. The easiest way to determine the reliability of a product is the statisti- 
cal analysis of historic failures. Since such information is not available for new products, tools with predictive capabilities are required.

Therefore, this paper proposes a method, which predicts the reliability of the whole system by using information available for the individual components of the system. In addition to the properties of the single components, influences from the environment, such as temperature and dirt contamination, are explicitly considered.

Earlier works focused mostly on tests to determine the reliability of components without evaluating reliability calculation methods. In addition, mostly gears and bearings were included in reliability determinations. Other components, which are also critical for the functioning of the system, such as seals, shafts and clutches have often not been included, either because their influence was considered irrelevant or because proper calculation methods were not available. Since all components must be taken into account for a reliable prediction of the whole system, we go beyond these previous works and consider more parts of the transmission Bertsche and Lechner (2004).

\section{State of the Art}

Mechanical components usually fail due to fatigue and wear. Because failures caused by fatigue are usually not recognizable before they appear, it is important to have fundamental knowledge about the transmission to predict fatigue failures. From reliability view, failures because of wear are less critical but often become apparent through increasing noise or vibrations Kopp (2013). To evaluate reliability, a precise definition, as well as the knowledge of what it is caused by, is needed. Reliability is defined as

The probability that a product does not fail during a defined period of time under given function and surrounding conditions Bertsche (2008).

In the following, the fundamentals of reliability analyses and lifetime calculations are described.

\subsection{Fundamentals of Reliability Analysis}

Since stress and strength of mechanical components are distributed statistically, the reliability of the components follows the rules of statistics as well (see Figure 2). Failure can occur, when the actual stress is higher than the strength of a component. To achieve the highest possible reliability, the component has to be designed such that the strength is substantially higher than the maximum stress. Such a design, however, causes high costs and might be inconsistent with other design requirements (e.g. space weight) Naunheimer et al. (2007). Therefore, a good design is characterized by the right balance between economical and durability considerations.

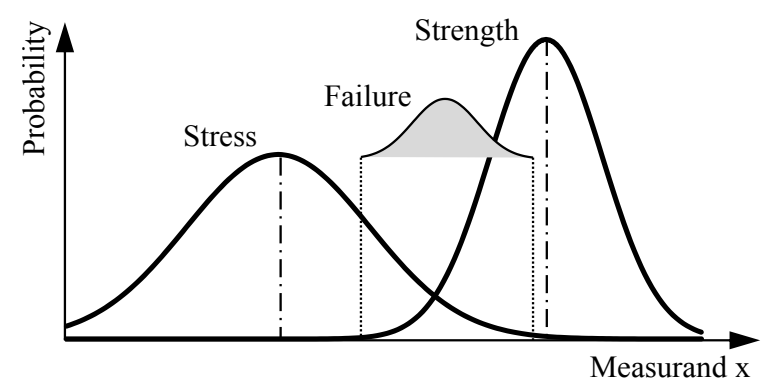

Figure 2: Stress-strength-interference Kopp (2013)

Reliability methods are used to predict the components' reliability. There are two kinds of reliability methods, qualitative and quantitative. Qualitative methods, e.g. the Failure Mode and Effect Analysis (FMEA), enable a systematic investigation of the effects of errors and failures; however, qualitative methods are not able to describe reliability changes over time. To get detailed information about how to design reliable parts and calculate maintenance costs in advance, quantitative methods are necessary.

In order to apply quantitative methods, the component loads and the component's failure behavior need to be mathematically described. According to the state of the art, the lifetime of cyclically loaded components can be calculated by damage accumulation hypotheses. For that, the loads are classified into different load classes and the number of load alternations is counted. By comparing the actual number of load alternations $n_{i}$ with the bearable number of load alternations $N_{i}$, the part damage per load level can be calculated. These part damages are then accumulated and yield the overall damage $S$. Whenever this damage $S$ reaches a value

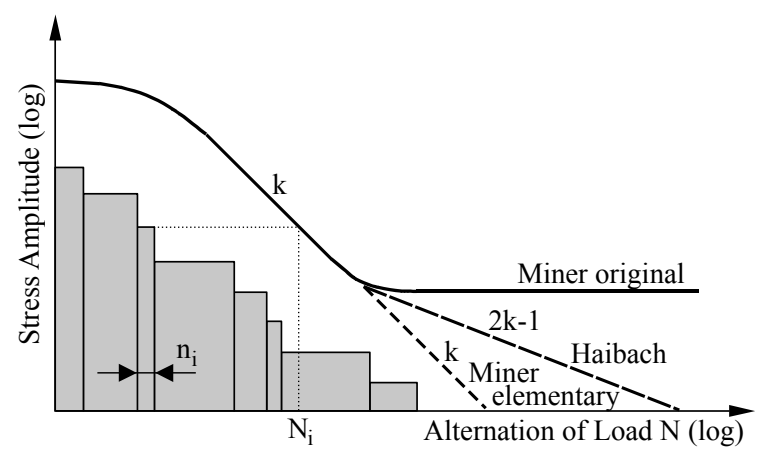

Figure 3: Damage accumulation hypotheses Wacker (2013) 
of "1", the component will fail per definition Haibach (2006). Three different hypotheses are illustrated in Figure 3.

A components failure behavior can be displayed as a histogram of its lifetimes. Figure 4 shows the lifetimes and the histogram of a stress test.

a)

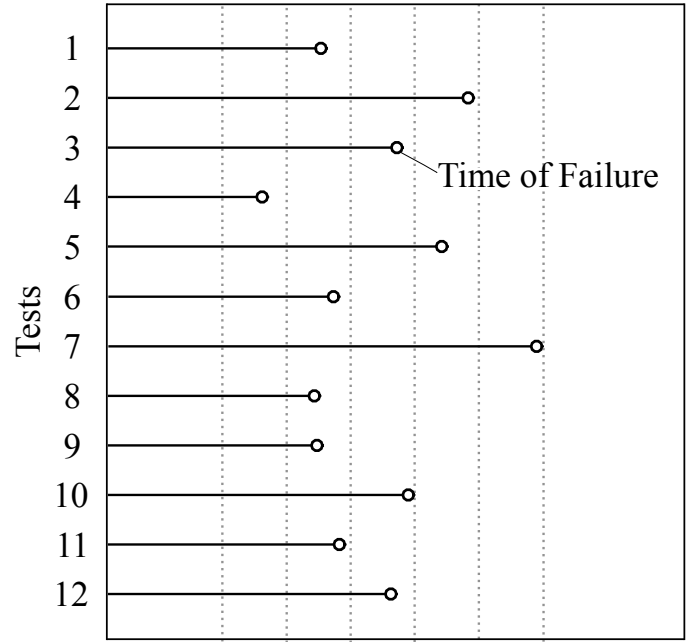

b)

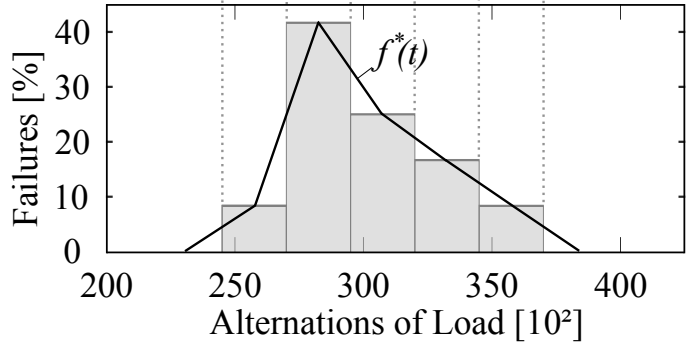

Figure 4: a) Lifetimes b) Histogram of lifetimes Bertsche and Lechner (2004)

The abscissa reflects the number of load alternations before the component fails. In the limit of a very large number of failure tests and small class widths, the empirical density function $f^{*}$ can be approximated by a continuous density function $f$. The density function describes the number of failures at the time $t$ or after $n$ load alternations, relatively to the total number of tests.

For many considerations, however, not the number of failures at a certain point in time is relevant, but rather the number of failures that occurred during a certain time period. This quantity can be described by the distribution function $F(t)$, usually referred to as the failure probability. $F(t)$ corresponds to the probability with which failures happen at a time $t$, and can be computed from the density function $f(t)$ according to Eq. (1). Yet another useful function is the survival probability function or just "Reliability", $R(t)$, which describes the probability with which a component has survived a certain time $t$, see Eq. (2). Bertsche and Lechner (2004)

$$
\begin{aligned}
F(t) & =\int_{0}^{t} f(\dot{t}) d t^{\prime} \\
R(t) & =1-F(t)
\end{aligned}
$$

To characterize reliability data the usage of parameters such as $B_{x}$ lifetime is common. $B_{x}$ lifetimes define the point in time after which $x \%$ of the components have failed statistically. For transmissions usually $B_{1}$ and $B_{10}$ are used. DIN 3990 (1987)

Several mathematical expressions have been used to represent reliability functions. Although the normal distribution has a high overall acceptance in science, this function is rarely used for the description in reliability engineering. Here, one of the most commonly used functions is the Weibull distribution. When using this expression, the failure probability function, survival probability function and density function are given by Eq. (3),(4) and (5). Bertsche and Lechner (2004)

$$
\begin{aligned}
F(t) & =1-e^{-\left(\frac{t-t_{0}}{T-t_{0}}\right)^{b}} \\
R(t) & =e^{-\left(\frac{t-t_{0}}{T-t_{0}}\right)^{b}} \\
f(t) & =\frac{b}{T-t_{0}} \cdot\left(\frac{t-t_{0}}{T-t_{0}}\right)^{b-1} \cdot e^{-\left(\frac{t-t_{0}}{T-t_{0}}\right)^{b}}
\end{aligned}
$$

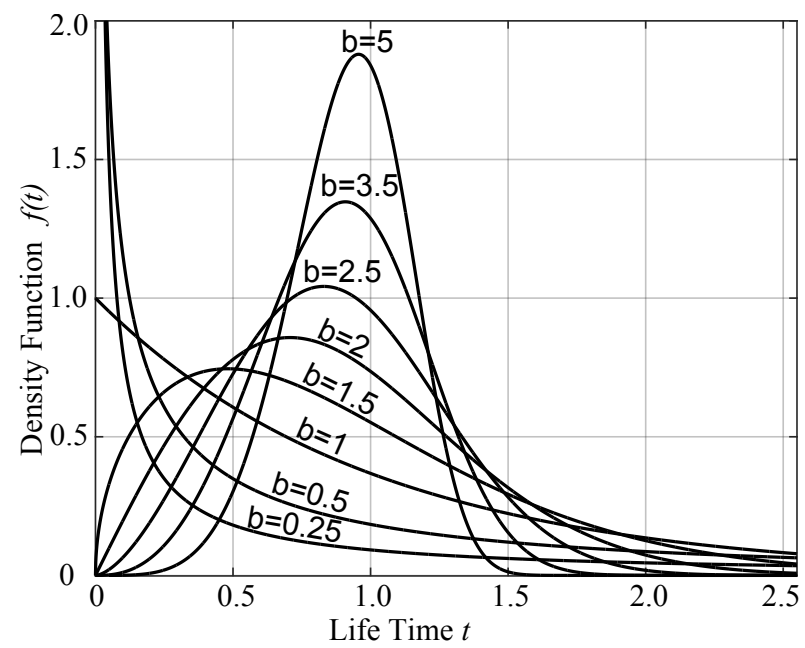

Figure 5: Weibull density functions for different shape parameters $b$ Bertsche and Lechner (2004)

By changing the shape parameter $b$, the Weibull distribution can be used to describe many different failure behaviors, see Figure 5. For $b=1$, the Weibull distribution is equivalent to the exponential distribution, for 
$b=3.5$, it is similar to the normal distribution. The characteristic lifetime $T$, or scale parameter, describes the mean value of the distribution. For $t=T$, the failure probability is $F(t=T)=63.21 \%$. With $t_{0}$ an initial time frame without any expected failures can be described.

Furthermore, failure of mechanical components can be divided into three categories Naunheimer et al. (2007):

1. Early failures due to faulty assembly, unsuited material or development errors. These kind of failures are not predictable and are commonly described by Weibull distributions with a shape parameter $b<1$.

2. Random failures due to errors while operating the system or maintenance failures. Like early failures, these failures are not predictable. Weibull Distributions with $b=1$ are suited for such failures.

3. Wearout failures due to fatigue and wear. These kind of failures are quantifiable. Therefore, they are the only kind of failures that are assessable in reliability calculations. A Weibull distribution with $b>1$ represents such behavior.

In the next section, the availability of methods to calculate the lifetimes of mechanical components is explained.

\subsection{Lifetime Calculation of Mechanical Components}

It is not possible or necessary to calculate a quantitative reliability for every mechanical component as the components of a transmission contribute with different weights to the overall reliability. To identify critical components an "ABC-analysis" is well suited. The $\mathrm{ABC}$-analysis is a simple qualitative method and is used in this context to evaluate components in terms of their impact on system reliability and availability of calculation methods. As shown in Figure 6, the categories contain the different mechanical components of a transmission, divided by the influence on the transmission's reliability and the availability of verified calculation methods.

Category A contains components that are relevant for the transmission's reliability and for which calculation methods are sufficiently accurate. Components categorized as "A" are e.g. gears, bearings and shafts. "B-components", e.g. friction clutches and seals, are components whose reliability is relevant for the transmission's reliability as well; however in contrast to Acomponents, their life expectancy cannot be predicted

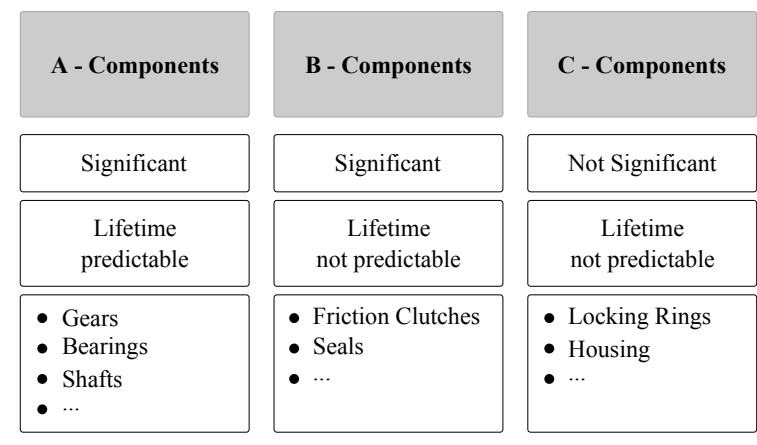

Figure 6: ABC-analysis of components Naunheimer et al. (2007)

with sufficient accuracy. Therefore, a statistical statement about the category B components is currently only possible by real life testing. Category $\mathrm{C}$ contains components that are not relevant for the reliability of the entire transmission and for which the lifetimes cannot be predicted. Typical elements of this category are components like housing and locking rings. Components of category A have to be divided even further to find every kind of failure. The actual failure distributions of each component cannot be calculated and have to be determined by testing. Usually, certain mechanical components have similar failure distributions. Early and random failures cannot be calculated for any of the described categories. Calculation methods for failures due to wear and fatigue for A-components and for several B-components are described in the next sections.

\subsubsection{Transmission Oil}

There are two different ways to take the transmission oil into consideration in the context of a reliability evaluation of a transmission. The first option treats the oil as an individual component of the system described by a separate failure probability function. In addition to that, the failures of oil can be divided into failures due to aging and failures arising from dirt contamination. The machine element oil fails whenever a predefined state is reached. An important requirement for this approach is the availability of a calculation method that is able to determine the lifetime of an oil.

As a second option, the oil can be taken into account by its influence on other mechanical components. The strength of the other components depends on the current state of the oil. Of course, this kind of calculation method requires information about the dependency of the component's strength on the oil condition. For bearings, such methods are used to calculate the strength against pitting based on dirt particles in the oil DIN ISO 281 (2010). For pitting failures of gears, 
a method for considering aged oil is available Maisch (2012).

\subsubsection{Gears}

Gears are designed based on the DIN 3990 (1987). The strength of gears depends on many parameters, such as material, geometry, manufacturing process, surface and environmental conditions. Failures of gears can arise either due to tooth fractures or due to pitting. Gears can fail due to scuffing as well. But as scuffing prediction of gears is not very well advanced and scuffing usually only occurs outside of predefined operating conditions, scuffing is currently not considered in reliability calculations Boog (2011).

Therefore, each gear has three different failure distributions; one for each tooth side representing pitting and one representing tooth fracture. While a tooth fracture ends the lifetime of gears immediately, pitting does not. At the beginning, pitting has only an effect on noise, wear and efficiency. Therefore, failures due to pitting are defined as the state when pitting reaches $4 \%$ of the tooth's surface Klocke and Pritschow (2004).

\subsubsection{Bearings}

The lifetime calculation of bearings has been standardized by the DIN ISO 281 (2010). Dirt particles in the lubricant have a large negative influence on the bearing's lifetime. While the lifetime calculation in DIN ISO 281 (2010) takes dirt particles only with qualitative factors into account, this method can be extended to calculated factors Rombach (2009). The only kind of bearing failure currently considered for reliability calculation is pitting. By referring to DIN ISO 281 (2010), a bearings strength regarding pitting can be determined.

\subsubsection{Shafts}

The design of shafts is standardized in DIN 743 (2012). Shafts in transmissions are stressed by alternating torques, as well as by bending and normal stresses, which result from forces applied by helical gearings. Furthermore, the geometry of the shafts has to be considered. Shaft shoulders, grooves and radii have a large influence on the internal stresses Naunheimer et al. (2007). With the availability of computer aided calculation methods based on DIN 743 (2012), it is relatively easy to calculate a shafts lifetime.

\subsubsection{Friction Clutches}

Although friction clutches belong to Category B, it is possible to obtain at least a rough estimation of their lifetimes. The lifetimes of friction clutches depend on material, time in use, lubricant, temperature, age and the relative velocity and load inside the clutch. There is an unverified method available to calculate an estimation of the lifetime by considering the wear of the clutch surfaces. A clutch is considered to have failed when a predefined state of wear is reached Hensel and Pflaum (2010). As there are too many influence parameters, there are no completely verified failure distributions available.

\subsubsection{Radial Shaft Seals}

Similar to clutches, seals belong to category B and verified lifetime calculation methods are not available. Seals have a very complex tribological system, which is hard to quantify. A rough estimation of the lifetime of a seal can be made by considering only the temperature and the aging caused by high temperatures. For this, an unverified method is available Haas et al. (2010). However, this method requires the temperature in the frictional contact and considers only failures due to thermal degradation.

\section{System Theory}

The previous sections explained the determination of the lifetime and failure distributions of mechanical components. To combine those individual distributions to the lifetime and failure distribution of an entire transmission, a system theory is necessary. There are several theories available and depending on the structure of the system, the kind of the components' failure distributions and whether or not it is supposed to be repaired within its lifetime, an optimal theory can be chosen. The system transport theory is considered to be the most extensive system theory Bertsche and Lechner (2004). Unfortunately, an application of this powerful method requires Monte-Carlo-Simulations. As the implementation of a Monte-Carlo-Simulation is a very elaborate process, it has so far not been applied to a reliability evaluation of a vehicle transmission in its full extent. The application of this theory would allow a prediction of the reliability of transmissions that are repaired during their lifetime. In this paper, however, it is assumed, that the system will not be repaired, and that Boole's system theory can be applied Bertsche and Lechner (2004).

In general, there are two basic ways to model the reliability structure of a technical system (see Figure 7). A serial structure represents a system without any redundant parts. If one component of a serial system fails, the whole system fails. A parallel structure represents a system with redundant parts. In this case, the system only fails, when all components have reached the 
end of their lifetime. By combining these two basic structures, it is possible to define the reliability structure of a complete technical system. Applying Boole's theory, the system reliability can then be calculated based on the individual component reliabilities according to Eq. (6) for serial structures or Eq. (7) for parallel structures.

$$
\begin{array}{r}
R_{S}(t)=\prod_{i=1}^{n} R_{i}(t) \\
R_{S}(t)=1-\prod_{i=1}^{n}\left(1-R_{i}(t)\right)
\end{array}
$$

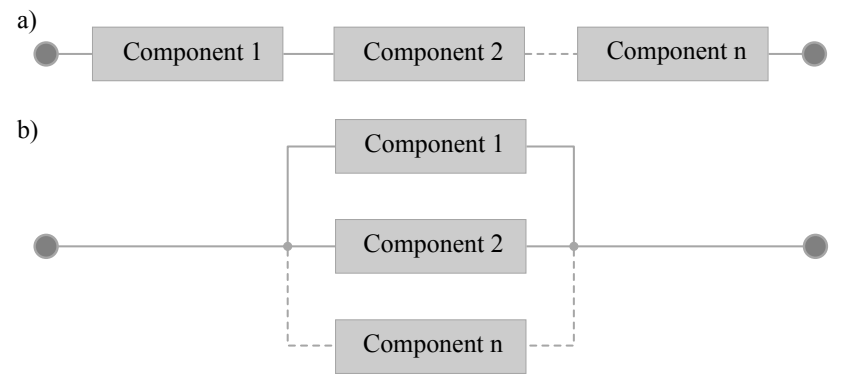

Figure 7: Reliability structure a) serial b) parallel

As can be observed in Eq. (6), the number of components is significant for the system's reliability and the failure probability grows exponentially with an increasing number of components. In contrast, the reliability of parallel systems increases with a rising number of redundant components, see Eq. (7).

\section{Method for Quantitative Reliability Evaluation of Technical Systems}

After having described the necessary basics and the chosen system theory, a detailed method for the quantitative evaluation of system reliability is proposed in Figure 8.

1. As a first step, all relevant mechanical components of the system have to be identified. For this, a qualitative method like a FMEA is applicable. In this analysis, not only the most important powertransmitting components, such as gears and bearings, need to be evaluated, but also less obvious (and often neglected) components have to be taken into account, such as shafts, seals, housings and the lubricant. Knowing the function of all components and how they interact with each other is crucial for the reliability evaluation.

2. As mentioned earlier, not all mechanical components or their kind of failures have the same influence on the system's reliability. To determine which failures of mechanical components are critical for the system, a qualitative analysis of the components, such as an ABC-analysis, is necessary. Although verified calculation methods for components such as friction clutches and seals in Category B are not available, several unverified methods have been proposed for calculating basic lifetimes. As clutches and seals are very complex, the prediction of their lifetimes is only possible on a very approximate level, and are currently suited for rough estimations only. Nevertheless, they are applied in this evaluation to take those components into account.

3. In the next step, the reliability structure has to be created. A reliability structure displays whether or not a system contains redundant components, and can be defined by a combination of serial and parallel structures.

4. To determine the loads on the system, a typical load cycle is necessary. This cycle can be determined either by an actual measurement or by a simulation. Actual measurements are preferable as they best represent reality, but simulated load cycles are usually sufficient for an evaluation Buck (1973).

5. The loads of each individual component have to be defined in this step, which is found through analytical or numerical calculations based on the external loads. To accomplish this, information about the dimensions of the system components are required. If the loads are functions of distance or time, these dependencies have to be considered explicitly and the loads need to be available as a function of their individual revolutions or load alternations.

6. To quantify the component loads, it is necessary to classify the loads and transfer them into specific component load spectra. Previous work suggested that 16-64 numbers of classes are sufficient Bertsche and Lechner (2004). For gears and seals, the time-at-level procedure has been found to be suited best Renius (1977), while for shafts the Rainflow method is usually applied.

7. To calculate the strength of the components, an analysis of the environmental conditions has to be 


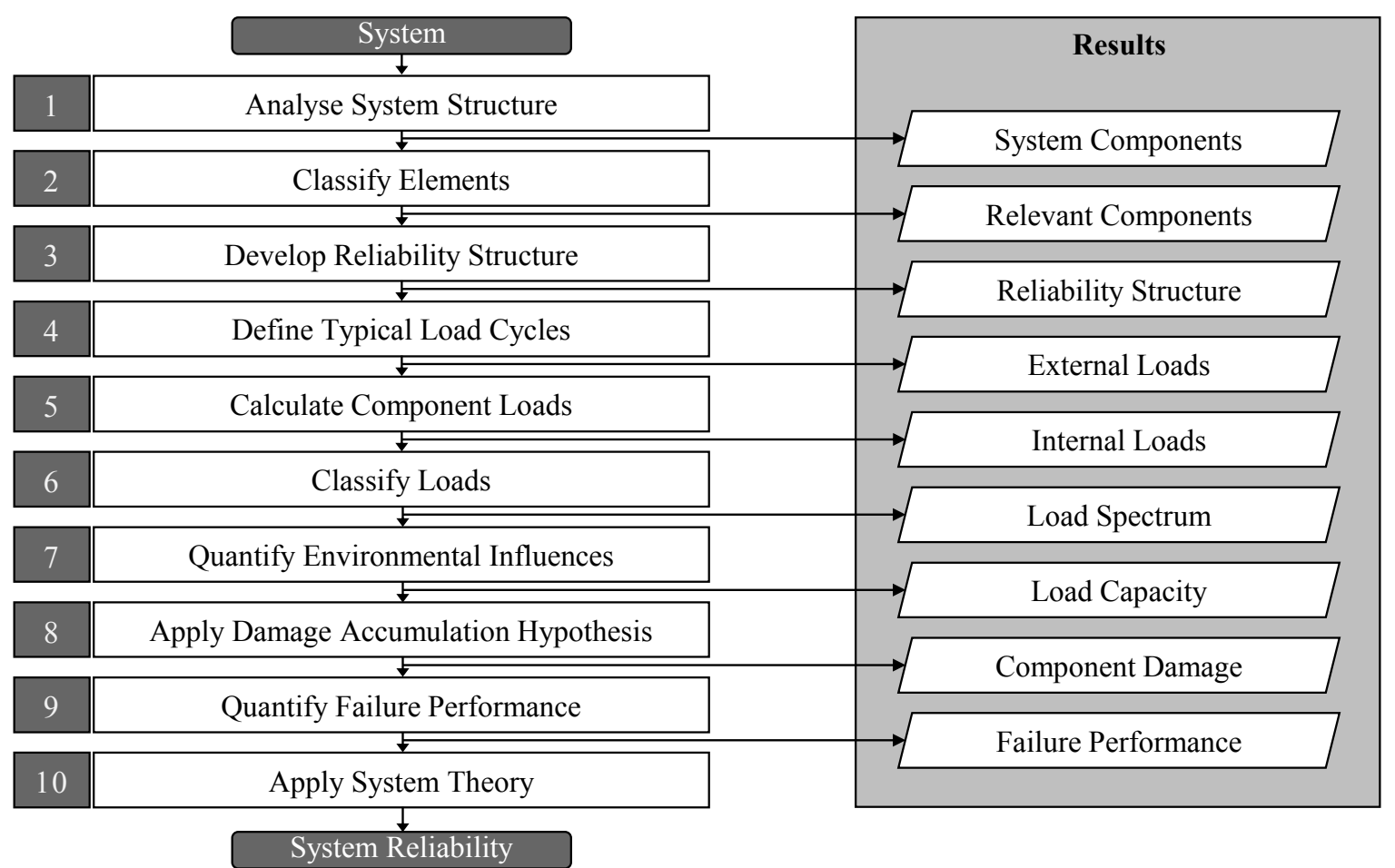

Figure 8: Method for reliability evaluation of technical systems

performed. Parameters like the temperature, the oil condition and the number of dirt particles have a big influence on the durability of certain machine elements. Due to that, it is necessary to analyze and quantify the influences thoroughly.

8. For the determination of the actual lifetime, the calculated stresses and strengths need to be connected by a suitable damage accumulation hypothesis. By applying such hypotheses, the damage for each individual component can be calculated for the provided load cycle, and the residual lifetime can be calculated.

9. The related failure distributions for the components can be determined by tests or by historical data. It has been shown, that the failure distributions of mechanical components are usually described by Weibull distributions with shape parameters $b>1$. The ranges of the Weibull Parameters for different components and failures are given in Bertsche and Lechner (2004).

10. When the lifetimes and failure distributions for all components are known, the overall reliability and the failure probability function can be calculated. To do so, a system theory has to be selected. Among multiple different theories, Boole's Theory is the most suitable one to determine the reliabil- ity of non-repairable systems. The availability of the system is equivalent to the reliability.

\section{Application of Method}

After having described the method for reliability evaluations, this method is applied to a heavy-duty power shift transmission with an input power range of 67 $97 \mathrm{~kW}$. This transmission can be used for utility vehicles such as forklifts, wheel loaders and dumpers. The input torque at the torque converter can be around $800 \mathrm{Nm}$. The shifting between the three speeds for forward and reverse drive occurs without power interruption. To achieve that, the transmission contains five friction clutches (see Figure 9).

Engaging and disengaging clutches FWD and RWD switches between forward and reverse gear. In combination with the clutches $1 \mathrm{ST}, 2 \mathrm{ND}$ and $3 \mathrm{RD}$ a speed is selected. Therefore, there are always two clutches engaged, and the remaining three are disengaged, see Figure 9. Furthermore, the transmission contains ten gears that are always engaged, 18 bearings, seven shafts and two radial shaft seals. For lubrication, a mineral oil with a kinematic viscosity of $\nu_{40}=100 \frac{\mathrm{mm}^{2}}{\mathrm{~s}}$ is assumed. The oil temperature is defined as a constant of $80^{\circ} \mathrm{C}$. As discussed earlier, the oil can be considered by two different options. Here, the oil is taken into ac- 


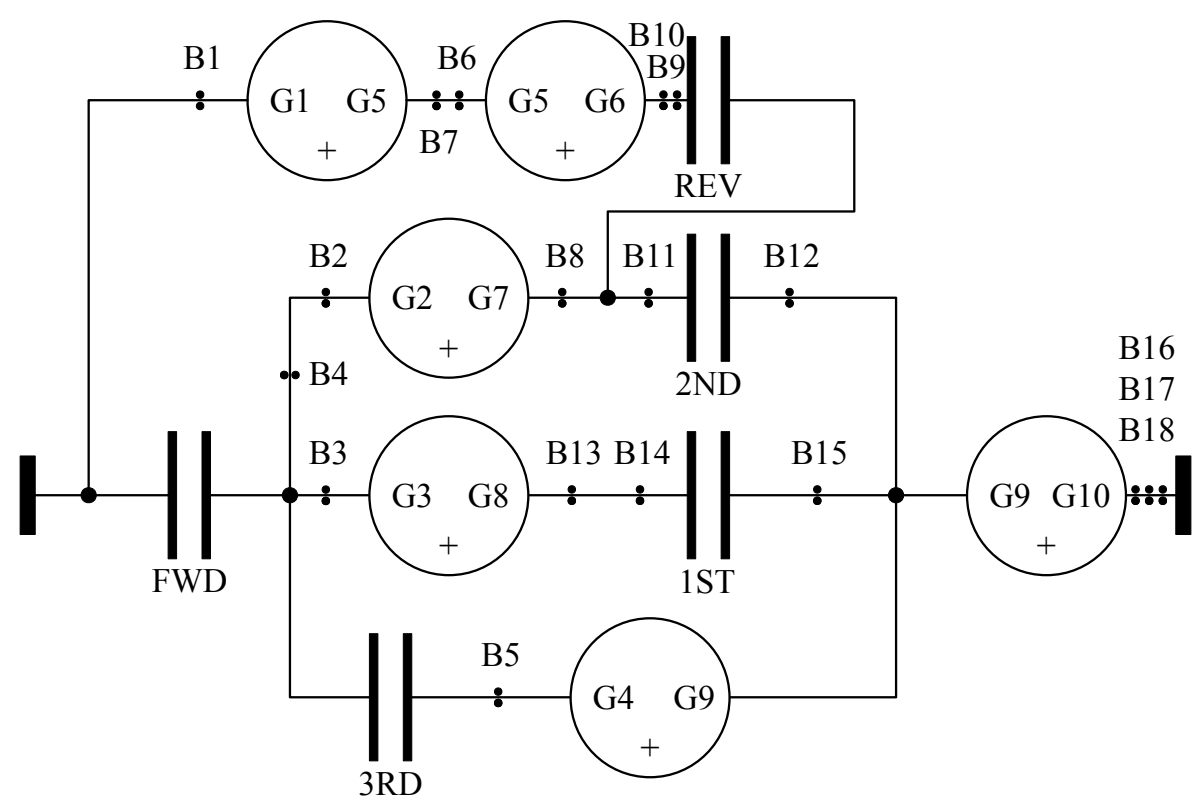

Figure 9: Torque plan

count as an influence on the mechanical components, and not as an individual component.

The external loads have been calculated by a simulation of a driving cycle. The assumption for the simulation is a fictional dumper with a driving power of $95 \mathrm{~kW}$ that is used in a quarry. The dumper has an empty weight of $10 \mathrm{t}$ and a payload of additional $10 \mathrm{t}$.
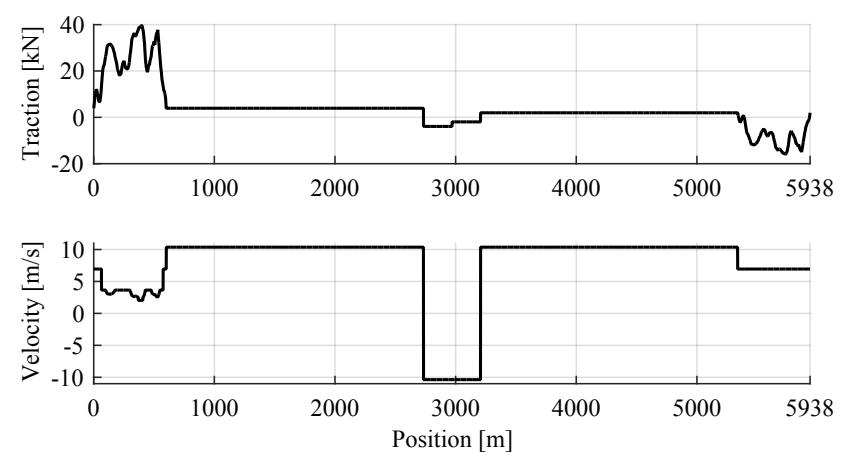

Figure 10: Driving cycle of a fictional dumper in a quarry, data from Rebholz et al. (2014)

The driving cycle (Figure 10) includes a driving distance of about $6,000 \mathrm{~m}$, which takes 12 minutes. The dumper is loaded in the bottom of the quarry, then drives uphill out of the quarry, travels a certain distance straight, unloads and goes back the same way. In addition to the driving resistance caused by the slope, a rolling resistance of $2 \%$ of the vehicle's weight has been added. The resulting traction and velocity is simulated based on measured data of the elevation-time- course of a real dumper driving in a quarry. During the simulated driving cycle, only four of the six transmission speeds are used. During $83.4 \%$ of the distance, the third forward gear is engaged. The second forward gear and the third reverse gear have both a time-share of $8 \%$. The first forward gear has a share of only $0.6 \%$. Nevertheless, all of the gears are under load at least once throughout each driving cycle.

It is assumed that the transmission is not repaired so that the first failure of a component ends the transmission's lifetime. With this assumption, the Boole's theory is applicable to calculate the system's reliability based on the failure distributions of the components. The components' lifetimes are calculated based on the external conditions of the transmission. In addition to the components in category A, bearings and gears, for which verified methods are available, the lifetimes of the seals and friction clutches are calculated by using unverified calculation methods.

For the estimation of the lifetime of the seals, the temperature-dependent Arrhenius-model is used. For this calculation model only the oil sump temperature $T_{K}$ and empirical material factors are necessary. When using the usual seal material Nitrile Butadiene Rubber, the lifetime of a seal can be calculated according to Eq. (8) Haas et al. (2010).

$$
L_{\mathrm{NBR}}=8.54 \cdot 10^{-7} \cdot e^{\frac{7905}{273.15+T_{K}}}
$$

The lifetime of friction clutches can be approximated by assuming that the wear volume is proportional to the friction energy. By using an empirical materialdependent friction coefficient $f_{F r i c}$, the duration per 
switch operation $t_{i}$, number of switch operations $j$ per driving cycle, the relative turning speed $n_{i}$ and the clutch torque $M_{K}$, the wearing volume $V$ of a defined driving cycle can be determined (see Eq. 9).

$$
\Delta V=\sum_{i=1}^{j} \Delta n_{i} \cdot \pi \cdot M_{K_{i}} \cdot \Delta t_{i} \cdot f_{\text {Fric }}
$$

The clutch is considered failed, as soon as the wear volume reaches a predefined threshold $V_{\text {limit }}$ Niemann et al. (2004).

After having determined the lifetimes of the components, the individual failure distributions can be built by referring to existing Weibull parameters (see Table 1).

Table 1: Weibull parameters of failure distributions Bertsche and Lechner (2004)

\begin{tabular}{|c|c|c|c|}
\hline Component & Failure & $f_{t B}$ & $b$ \\
\hline \hline Gear & Fracture & $0.8 \ldots 0.95$ & $1.2 \ldots 2.2$ \\
& Pitting & $0.4 \ldots 0.8$ & $1.1 \ldots 1.5$ \\
\hline $\begin{array}{c}\text { Ball Bearing } \\
\text { Roller Bearing }\end{array}$ & Pitting & $0.1 \ldots 0.3$ & $\begin{array}{c}1.1 \\
1.35\end{array}$ \\
\hline Shaft & Fracture & $0.7 \ldots 0.9$ & $1.1 \ldots 1.9$ \\
\hline Seal & Degr. & 0 & 1.85 \\
\hline Clutch & Wear & 0 & 3.5 \\
\hline
\end{tabular}

The initial period of time without failure $t_{0}$ is shown relative to the $B_{10}$-lifetime. The characteristic lifetime $T$ is calculated by:

$$
T=\frac{B_{x}-f_{t B} \cdot B_{10}}{\sqrt[b]{-\ln (1-x)}}+f_{t B} \cdot B_{10}
$$

with:

$$
B_{10}=\frac{B_{x}}{\left(1-f_{t B}\right) \cdot \sqrt[b]{\frac{\ln (1-x)}{\ln (0,9)}}+f_{t B}}
$$

For the failure distribution of the seals a Weibull distribution with a form parameter $b=1.85$ has been assumed, Haas et al. (2010). Due to the unavailability of a distribution for the friction clutches, a Weibull distribution with a form parameter $b=3.5$ has been defined. This distribution is similar to a normal distribution. Because the gear failures have been divided into pitting on both sides of the teeth and tooth fracture, the reliability structure contains 62 elements. As the analyzed transmission does not have any redundant parts, the reliability structure is completely serial.

Based on the geometry of the mechanical components, the external loads can be split and assigned to each individual component. Thus, each component has a load-time plot that has to be converted into a loadrevolution-plot to be quantified by a load spectrum with 16 classes. For the amount of particles in the oil, a linear variation in time of the oil particle factor $e_{c}$ has been added. This affects the strength of bearings. It is assumed that the amount of particles increases over the lifetime. The manufacturer of the transmission requires a change of the oil filter after every 500 hours of usage. The change of the oil filter is reflected in the calculation by a drop of the oil particle factor.

The resulting failure probability functions for both the entire power shift transmission and the different component groups are displayed in Figure 11.

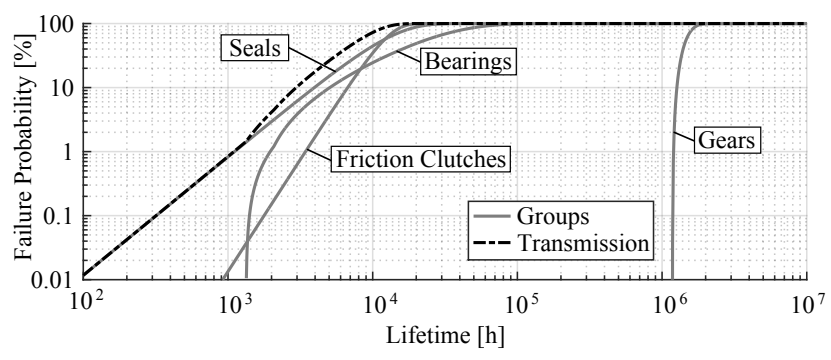

Figure 11: Failure probability

The radial shaft seals seem to be the critical components, having the biggest influence on the system's reliability. As the reliability calculation of the seals is fairly unverified, it might display the transmission as less reliable than it actually is. Bearings and friction clutches have a similar reliability. The gears, on the other hand, seem to be oversized, and are only slightly contributing to the failure probability of the entire transmission. The lifetime calculation of the shafts based on the external loads has been done according to DIN 743 (2012). According to the results, the shafts are heavily oversized and do not have any influence on the reliability of the transmission. Focusing only on the components in category $\mathrm{A}$, the bearings seem to be the critical mechanical components. The most critical bearing is the one near the output of the transmission (B15), as it is stressed all the time with high loads, see Figure 9. Theoretically, several bearings have an infinite lifetime since they are only put under load when their relative turning speed between outer and inner ring is zero (B4, B9, B10, B13 and B14).

The mean lifetimes of the component groups are displayed in Figure 12. The lifetimes of the components within the groups "gears", and "bearings" have a wide distribution. This is another indicator that the methods currently in use are not sufficient for an economic design process, as the target is to design all components with the same life expectancy.

A reason for the different lifetimes between the component groups might be the fact that the lifetime calcu- 


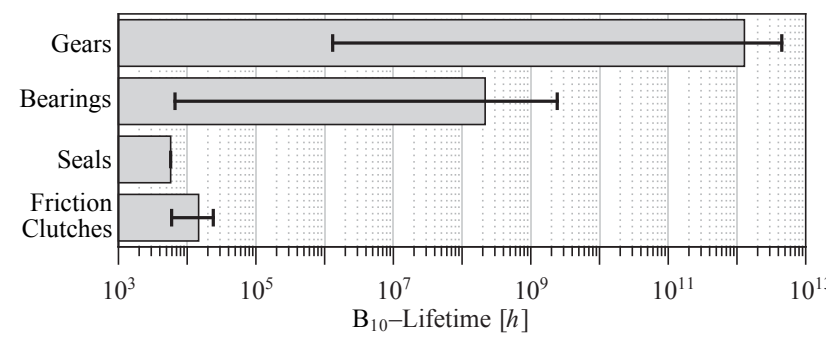

Figure 12: $B_{10}$-lifetimes

lation of bearings is fairly easy, as it is documented in engineering standards. For shafts and gears, only the calculation of their strength is described in engineering standards and the lifetime calculation has to be done manually by comparing stress and strength using appropriate damage accumulation hypotheses. Because of this, there might be a tendency to oversize components rather than spending time on reliability evaluations. An oversizing of $10 \%$ causes in general only $10 \%$ additional costs, but can double the lifetime of a transmission Naunheimer et al. (2007). However, for an economic design of a transmission, this is not an appropriate method.

In Figure 13, the influence of the driving cycle on the lifetime of the transmission is illustrated. As demonstrated, a reduction of the driving time between loading and unloading by $50 \%$ reduces the lifetime of the transmission by $40 \%$ since the amount of higher loads compared to the whole cycle increases. This shows the importance of the selection of a well-suited load cycle which represents the real use case of the vehicle.

\section{Conclusion}

Ensuring reliability of products becomes more and more important due to higher product complexity and customer demands. The qualitative reliability methods currently in use do not seem to be sufficient to achieve the target of designing systems with a sufficient reliability. Therefore, an improved method for the evaluation of system reliabilities has been proposed. This method provides a step-by-step guideline on how to identify critical mechanical components in a technical system and how to determine lifetime and failure probability functions of the individual components. It covers common mechanical components in transmissions and takes environmental influences such as aging, temperature and dirt particles in the lubricant into account.

The method has been applied to a real vehicle transmission of a fictional quarry-dumper. The results reveal that the seals, clutches and bearings and especially the bearing near the output of the transmission,

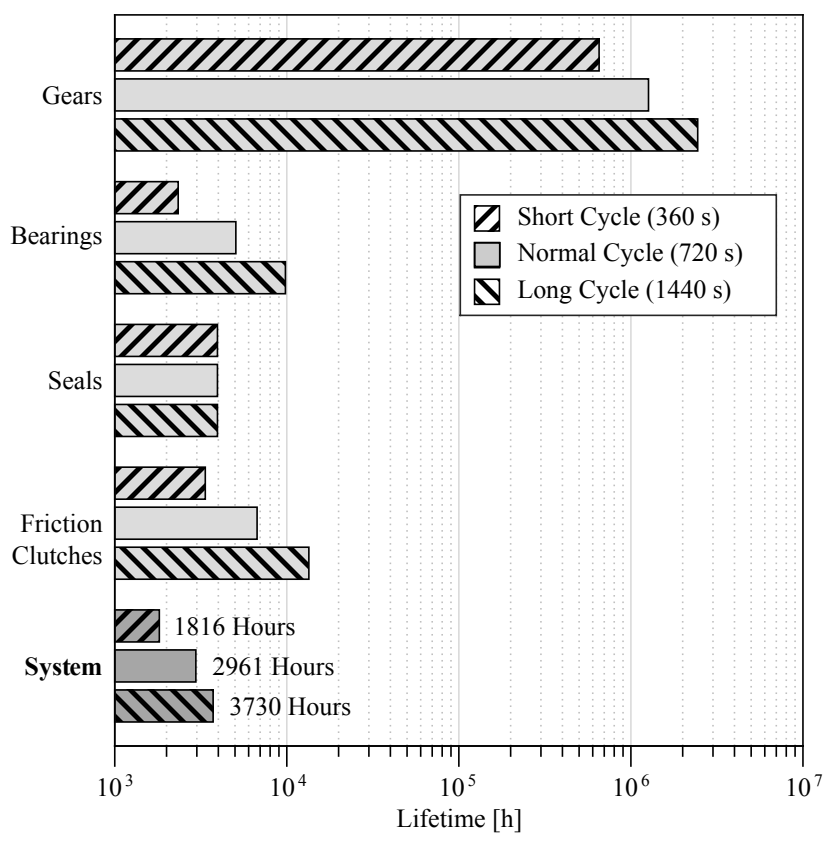

Figure 13: Influence of cycle length

seem to be the critical components, while the gears and shafts seem to be heavily oversized.

Based on such results, it is possible to design systems in a more economical way, without the risk of a decreasing reliability. The development costs can be reduced as only a small number of tests is necessary for reliability evaluations. In addition, the proposed method can generate knowledge about the current system state based on the individually experienced load history. Hence, unplanned system breakdowns can be avoided and predictive maintenance strategies can be developed. Furthermore, because the main causes of failures can be predicted, selective condition monitoring concepts can be applied.

In the future, more verified calculation methods for the reliability evaluation of components used in technical systems should be developed so that the accuracy of future reliability evaluations can be improved. Additionally, in order to calculate repairable systems, it is also necessary to find more efficient algorithms to solve the equations of more complex system theories.

\section{Acknowledgments}

The research presented in this paper has received funding from the Norwegian Research Council, SFI Offshore Mechatronics, project number 237896. 


\section{References}

Bertsche, B. Reliability in automotive and mechanical engineering: Determination of component and system reliability. VDI-Buch. Springer, Berlin, 2008. doi:10.1007/978-3-540-34282-3.

Bertsche, B. and Lechner, G. Zuverlässigkeit im Fahrzeug- und Maschinenbau: Ermittlung von Bauteil- und System-Zuverlässigkeiten. VDI-Buch. Springer, Berlin, 2004. doi:10.1007/3-540-34996-0.

Boog, M. Steigerung der Verfügbarkeit mobiler Arbeitsmaschinen durch Betriebslasterfassung und Fehleridentifikation an hydrostatischen Verdrängereinheiten. Dissertation, KIT, Karlsruhe, 2011.

Buck, G. Probleme bei der Berechnung von Fahrzeuggetrieben mit Lastkollektiven: Lastkollektivermittlung, Lebensdauerberechnung von Zahnrädern und Wälzlagern, volume 195 of Verein Deutscher Ingenieure: VDI-Berichte. VDI-Verl., Düsseldorf, 1973.

DAT. Deutsche Automobil-Treuhand GmbH Report. KFZ-Betrieb : Dossier. Deutsche AutomobilTreuhand, Ostfildern, 2015.

Dette, H. and Kozub, C. Bis das Getriebe kracht: Statistik ersetzt teure Tests, volume 1/00 of RUBIN Wissenschaftsmagazin, Ruhr-Universitt Bochum. 2000.

DIN 3990. Tragfähigkeitsberechnung von Stirnrädern Einführung und allgemeine Einflussfaktoren. Beuth, 1987.

DIN 743. Tragfähigkeitsberechnung von Wellen und Achsen - Teil 1: Grundlagen. Beuth, 2012.

DIN ISO 281. Wälzlager - Dynamische Tragzahlen und nominelle Lebensdauer. Beuth, 2010.

Haas, W., Hörl, L., and Klein, B. Betrachtungen zur Zuverlässigkeit und Lebensdauer von Hydraulikdichtungen. 2010. URL http://www.ima.uni-stuttgart.de/ima_ downloads/dichtungstechnik/Betrachtungen_ zur_Zuverlaessigkeit_und_Lebensdauer_von_ HSDR . pdf.

Haibach, E. Betriebsfestigkeit. VDI-Buch. Springer, Berlin, 2006. doi:10.1007/3-540-29364-7.

Hensel, M. and Pflaum, H. Lebensdauer Lamellenkupplungen: Untersuchung der Einflussgrößen
Hensel, M. and Pflaum, H. Lebensdauer Lamellenkupplungen: Untersuchung der Einflussgrößen auf die Lebensdauer und Leistungsgrenzen von nasslaufenden Lamellenkupplungen ; Definition einer Methode zur Abschätzung der Lebensdauer ; Entwicklung eines Lebensdauertests ; Abschlussbericht ; Forschungsvorhaben Nr. 515 I, volume 928. Forschungsvereinigung Antriebstechnik, Frankfurt, 2010 .

Klocke, F. and Pritschow, G. Autonome Produktion. Springer, Berlin, 2004. doi:10.1007/978-3-642-185236.

Kopp, M. Modularisierung und Synthese von Zuverlässigkeitsmethoden. Dissertation, Universität Stuttgart, Stuttgart, 2013.

Maisch, C. Berücksichtigung der Ölalterung bei der Lebensdauer- und Zuverlässigkeitsprognose von Getrieben. Dissertation, Universität Stuttgart, Stuttgart, 2012.

Naunheimer, H., Bertsche, B., Lechner, G., Ryborz, J., and Novak, W. Fahrzeuggetriebe: Grundlagen, Auswahl, Auslegung und Konstruktion. VDI-Buch. Springer, Berlin, 2007. doi:10.1007/978-3-662-071793.

Niemann, G., Hirt, M., and Winter, H. Maschinenelemente: Band 3: Schraubrad-, Kegelrad-, Schnecken, Ketten-, Riemen-, Reibradgetriebe, Kupplungen, Bremsen, Freiläufe, volume 3. Springer, Berlin, 2004. doi:10.1007/978-3-642-17468-1.

Rebholz, W., Riedhammer, M., and Jaeger, L. Performance and Efficiency Comparison of 8-Speed Powershift Transmissions to Planetary Transmissions in Dump Trucks. VDI Tagung Getriebe in mobilen Arbeitsmaschinen. Friedrichshafen, 2014.

Renius, K. Betriebsfestigkeitsberechnungen von Maschinenelementen in Ackerschleppern mit Hilfe von Lastkollektiven, volume 29 of Konstruktion. Springer-VDI, 1977.

Rombach, V. Prognose des Partikelgehalts in Getriebeölen zur erweiterten Berechnung der Lebensdauer von Wälzlagern. Dissertation, Rheinisch-Westfälische Technische Hochschule Aachen, Aachen, 2009.

Wacker, M. Einfluss von Drehungleichförmigkeiten auf die Zahnradlebensdauer in Fahrzeuggetrieben. Dissertation, Universität Stuttgart, Stuttgart, 2013. 